\title{
GEOLOGIA DO COMPLEXO METACARBONATÍTICO DE ANGICO DOS DIAS, DIVISA BAHIA/PIAUÍ, BRASIL.
}

\author{
GEOLOGY OF THE ANGICO DOS DIAS METACARBONATITE COMPLEX, BAHIA/PIAUÍ \\ BORDER, BRAZIL.
}

\author{
Rejane Lima LUCIANO ${ }^{1}$ \& Antonio Misson GODOY ${ }^{2}$ \\ (1) Programa de Pós-Graduação em Geociências e Meio Ambiente, Instituto de Geociências e Ciências Exatas \\ Companhia Baiana de Pesquisa Mineral - CBPM \\ Av. Quarta, no 460, Centro Administrativo da Bahia, Salvador, BA, 41.745-002 \\ Endereço eletrônico: rejane.lima@cbpm.ba.gov.br \\ (2) Departamento de Petrologia e Metalogenia, Instituto de Geociências e Ciências Exatas \\ Universidade Estadual Paulista - UNESP \\ Av. 24A, 1515, Bela Vista, CEP 13506-900. Rio Claro, SP. \\ Endereço eletrônico: mgodoy@rc.unesp.br
}

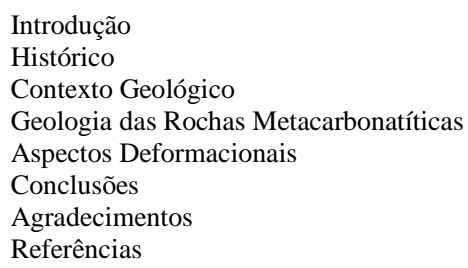

\begin{abstract}
RESUMO - As rochas paleoproterozoicas do Complexo Metacarbonatítico de Angico dos Dias são intrusivas em rochas gnáissicas migmatíticas arqueano-paleoproterozoicas do Complexo Sobradinho-Remanso e se situam na interface entre o Cráton São Francisco e as faixas móveis Formosa do Rio Preto e Riacho do Pontal. O complexo é constituído por metacarbonatitos, metassienitos variados, metapiroxenitos, metadioritos alcalinos, tremolititos e metalamprófiros. As rochas são classificadas principalmente como calciocarbonatito e constituídas dominantemente por calcita e apatita e, subordinadamente dolomita, olivina, flogopita e magnetita. As rochas metacarbonatíticas exibem variação no conteúdo de apatita, minerais ferro-magnesianos e magnetita, constituindo um acamamento magmático cumulático que permite individualizar vários litotipos petrográficos. Além disso, exibem manto intempérico, que resulta no minério de fosfato residual, denominado de apatitito. O quadro estrutural e metamórfico é identificado por deformações paleoproterozoicas $\mathrm{S}_{-2}$ e $\mathrm{S}_{-1}$, além de um acamamento reliquiar $\mathrm{S}_{0}$, localmente preservado devido à forte transposição das foliações neoproterozoicas $S_{1}$ e $S_{2}$, associadas às zonas de cavalgamento e relacionada às fases colisionais iniciais, com espessamento crustal. A deformação de caráter milonítica $S_{3}$ ocorre superposta às feições planares. As rochas do complexo encontram-se metamorfizadas em fácies anfibolito alto, apresentando paragêneses retrometamórficas em xisto verde médio a alto, além de caracterizarem localmente processos de fenitização e silicificação.
\end{abstract}

Palavras-chave: Carbonatito; Geologia Regional; Modelo Estrutural, Metamorfismo.

\begin{abstract}
Paleoproterozoic rocks from Angico dos Dias Metacarbonatite Complex (MCCAD) are intrusive in ArcheanPaleoproterozoic migmatitic gneissic rocks of Sobradinho-Remanso Complex, located at the interface between the Craton of São Francisco and Formosa do Rio Preto and Riacho do Pontal fold belts. The complex consists of metacarbonatites, varied metasyenites, metapyroxenites, alkaline metadiorites, tremolitites and metalamprophyres. The rocks are mainly classified as calcium carbonatite and consist predominantly of calcite and apatite and subordinate dolomite, olivine, phlogopite and magnetite. The metacarbonatitic rocks exhibit variation in the content of apatite, iron-magnesium minerals and magnetite, forming a cumulatic magmatic layering allowing individualizing various petrographic rock types. In addition, exhibit a weathering mantle, which results in the residual phosphate ore, called apatitite. The structural and metamorphic framework is identified by Paleoproterozoic deflections $\mathrm{S}_{-2}$ and $\mathrm{S}_{-1}$ and a reliquiar layering $S_{0}$, locally preserved due to the heavy implementation of Neoproterozoic foliation $S_{1}$ and $S_{2}$, associated to the thrust zones and related to the early collisional phases, with crustal thickening. The deformation of mylonitic character $\left(\mathrm{S}_{3}\right)$ is superimposed on planar features. The rocks of the complex are metamorphosed to high amphibolite facies, presenting retrometamorphic parageneses over medium to high green schist facies, as well as locally characterize fenitization and silicification processes.
\end{abstract}

Keywords: Carbonatite; Regional Geology; Structural Model; Metamorphism.

\section{INTRODUÇÃO}

Os primeiros trabalhos publicados sobre carbonatitos no Brasil reportam a Leonardos (1956), que estudou carbonatitos com apatita e pirocloros na região do Triangulo Mineiro. Entretanto, o carbonatito de Jacupiranga, no estado de São Paulo, foi descoberto por Bauer (1877) e, primeiramente descrito por Derby (1891) e Hussak (1892), mas somente com a exposição de quase todo o corpo, devido à exploração de fosfato, os dados para detalhamento foram obtidos por Melcher (1962). 
As idades das ocorrências brasileiras de corpos alcalinos/carbonatíticos são na maioria mesozoicas e cenozoicas subordinadas. Alguns raros complexos alcalinos no segmento norte amazônico são de idades neo- a mesoproterozoicas e o único complexo paleoproterozoico apresentando idade de 2.011 $\pm 6 \mathrm{Ma}$ (Mariano, 1987) identificado é o de Angico dos Dias.

A individualidade deste magmatismo também é destacada por Lapin et al. (1999), que expuseram uma síntese dos complexos carbonatíticos-feníticos pré-cambrianos, de natureza sintectônica e que se destacam pela morfologia linear dos seus corpos, associados a cinturões móveis e a falhamentos profundos, sendo o de Angico dos Dias o único do gênero conhecido no Brasil, em contraponto a todos os demais complexos alcalino-carbonatíticos brasileiros fanerozoicas, do Tipo Central, circulares a ovalados e intrudidos predominan- temente em ortoplataformas.

Atualmente, raras ocorrências de rochas carbonatíticas no Brasil estão em fase de exploração principalmente para fosfato e nióbio. Comin-Chiaramonti \& Gomes (2005) apontam somente as ocorrências de rochas carbonatíticas de Araxá, Catalão I, Catalão II, Jacupiranga e Tapira, além de Angico dos Dias.

A identidade e a importância genética única do corpo de metacarbonatito de Angico dos Dias necessitam de novos dados geológicos, petrográficos e geoquímicos (Luciano, 2016), que possam ser acrescidos à vasta bibliografia da região, contudo poucas dedicadas ao estudo específico do Complexo Metacarbonatítico de Angico dos Dias (CMCAD). Nesse sentido, pretende-se, com este trabalho, apresentar dados geológicos, permitindo assim uma melhor compreensão da história evolutiva dessas rochas e da sua potencialidade econômica.

\section{HISTÓRICO.}

Os trabalhos iniciais sobre esta ocorrência de rochas metacarbonatíticas foram publicados na década de 1970, a partir de associações minerais, com os primeiros indícios de mineralizações na área dados pela presença de vermiculita em superfície. As ocorrências minerais são referidas pela primeira vez na literatura geológica no Relatório Final do Projeto Piauí I, em escala 1:250.000, o Minério de Fe-Ti-V de Campo Alegre de Lourdes (Caldasso et al., 1973).

A Companhia Baiana de Pesquisa Mineral (CBPM) iniciou suas atividades geológicas preliminares na região e distritos circunvizinhos de interesse econômico em 1976/1977, com o Projeto Campo Alegre de Lourdes-Fase I (Lima, 1977), envolvendo principalmente os corpos mineralizados em Fe-Ti-V.

As pesquisas iniciaram propriamente a partir da execução do Projeto Ferro-Titânio de Campo Alegre de Lourdes-Fase II (Salviano et al., 1979) e os estudos geológicos também abrangeram o distrito de Angico dos Dias, que é um segmento do município de Campo Alegre de Lourdes.

Na década de 1980, após a descoberta de fosfato em Angico dos Dias, os estudos direcionados à investigação econômica das rochas do complexo carbonatítico foram $\mathrm{o}$ enfoque, em 1984, do Programa Carbonatitos pela Companhia Brasileira de Metalurgia e Mineração (CBMM).

Estas pesquisas geológicas iniciais da CBMM resultaram nos trabalhos de Silva et al. (1987; 1988), que apresentam as rochas do Complexo Metacarbonatítico de Angico dos Dias constituídas dominantemente por carbonatitos, sienitos, piroxenitos, dioritos alcalinos e lamprófiros metamorfizados, inserido no contexto geológico entre o Cráton São Francisco e as faixas moveis Formosa do Rio Preto e Riacho do Pontal.

A partir de 1997, com a conclusão do Mapeamento Geológico/Metalogenético, na escala 1:100.000, das Folhas de Campo Alegre de Lourdes \& Peixe (Leite, 1997), as informações coletadas consolidaram significativamente o quadro geológico da ocorrência de fosfato de Angico dos Dias. A partir de Silva et al. (1997) o depósito de fosfato de Angico dos Dias foi inserido no grupo dos principais depósitos minerais de fosfato do Brasil.

Os trabalhos de pesquisa executados pela CBPM relacionados ao Projeto Campo Alegre de Lourdes-Fase III (Moraes, 2006) complementaram os estudos em subsuperfície a partir de perfurações dos corpos/depósitos anteriormente mapeados. 
Liberal \& Cassola (1989) publicaram o primeiro trabalho a respeito do depósito de fosfato de Angico dos Dias, no qual abordam a geologia, o beneficiamento e o aproveitamento econômico do minério. Posteriormente, Kahn et al. (1990), Neumann \& Alcover (1999) e Santos (2001) tratam especificamente da natureza da apatita nas frentes de lavra e do aproveitamento econômico do minério. Esses autores apontam que o minério se originou a partir da ação intempérica atuante sobre o metacarbonatito e que depende diretamente do grau de alteração da rocha e, consequentemente, caracterizaram o minério primário e o residual ou eluvionar, significativamente mais rico em apatita.

As atividades de mineração tiveram início somente em 2005, por meio de tecnologia de concentração a seco, processo Humifert (Silverol, 2006), superando desse modo o grande desafio do empreendimento, a falta de infraestrutura hídrica local, pela Empresa GALVANI - Unidade de Mineração de Angico dos Dias.

\section{CONTEXTO GEOLÓGICO}

O Complexo Metacarbonatítico de Angico dos Dias está inserido no contexto do limite do Cráton São Francisco, proposto por Almeida (1977), ou, mais precisamente, no limite do extremo-setentrional do Domínio Tectônico "Corredor do Paramirim" (Alkmim et al., 1993), com as faixas de dobramentos marginais Formosa do Rio Preto e Riacho do Pontal e o domínio fisiográfico do norte da Cordilheira do Espinhaço Setentrional (Figura 1A). As rochas inserem-se no extremo norte do segmento geológico do Bloco Gavião (Barbosa \& Sabaté, 2004), localizado na porção central do Cráton São Francisco. As rochas se dispõem em dois conjuntos: o corpo principal localizado na mina de fosfato da Galvani e o outro de expressão restrita na Fazenda Pimenteiras (Figura 1B).

As rochas do complexo, assim como as rochas da Província Toleítico-Alcalina de Campo Alegre de Lourdes, estão intrudidas em uma associação de rochas gnáissicas e migmatíticas bandadas, de idade arqueanopaleoproterozoica do Complexo GnáissicoMigmatítico Sobradinho-Remanso, sendo as rochas da província consideradas contemporâneas às rochas carbonatíticas (Leite, 1997).

$\mathrm{O}$ posicionamento geotectônico das rochas do complexo reflete um arcabouço tectônico neoproterozoico, expresso por dobramentos, cavalgamentos e transcorrências, afetando gnaisses e migmatitos do embasamento arqueano-paleoproterozoico, rochas supracrustais, uma suíte granítica alcalina e complexos toleiíticos e carbonatíticos (Leite \& Santos, 1994). Essa conjunção de dados indica que a evolução tectônica experimentou períodos expressivos de distensão crustal, necessário e suficiente para permitir a ascensão de material magmático das partes profundas da litosfera (Santos, 2001).

$\mathrm{O}$ contexto geotectônico associado à origem das rochas carbonatíticas está essencialmente relacionado a um ambiente anorogênico em crosta continental, vinculado às zonas de grandes rebaixamentos (riftes). Nestas regiões, os carbonatitos situam-se preferencialmente nas zonas de inflexão das placas continentais, nas bordas de megafraturamentos. Embora sejam comuns províncias alcalinas desprovidas de carbonatitos, o inverso é extremamente raro e mais restrito.

A ocorrência de manifestações carbonatíticas, às quais se associam as mineralizações de fosfato, parece necessitar de um ambiente continental, com crosta espessa e bem evoluída, e do rompimento desta crosta por estruturas de grandes proporções, que atinjam o manto (Santos, 2001).

Segundo Santos (2001) podem ser identificados pelo menos três eventos anorogênicos nesta área. O primeiro evento é indicado pelos dados das assinaturas geoquímicas dos corpos ígneos plutônicos que mostram colocação e cristalização de magmas toleiíticos e alcalinos em ambiente continental paleoproterozoico, a partir de mecanismos de rifteamento ou domeamento crustal, gerados por plumas mantélicas (Leite et al., 1993). O segundo evento distensivo é registrado pela presença de sedimentação Espinhaço cuja fase rifte foi iniciada após o evento anorogênico transamazônico (1.800Ma) e o terceiro evento corresponde à instalação da Sinéclise do Parnaíba, que ocorreu durante o Fanerozoico. 


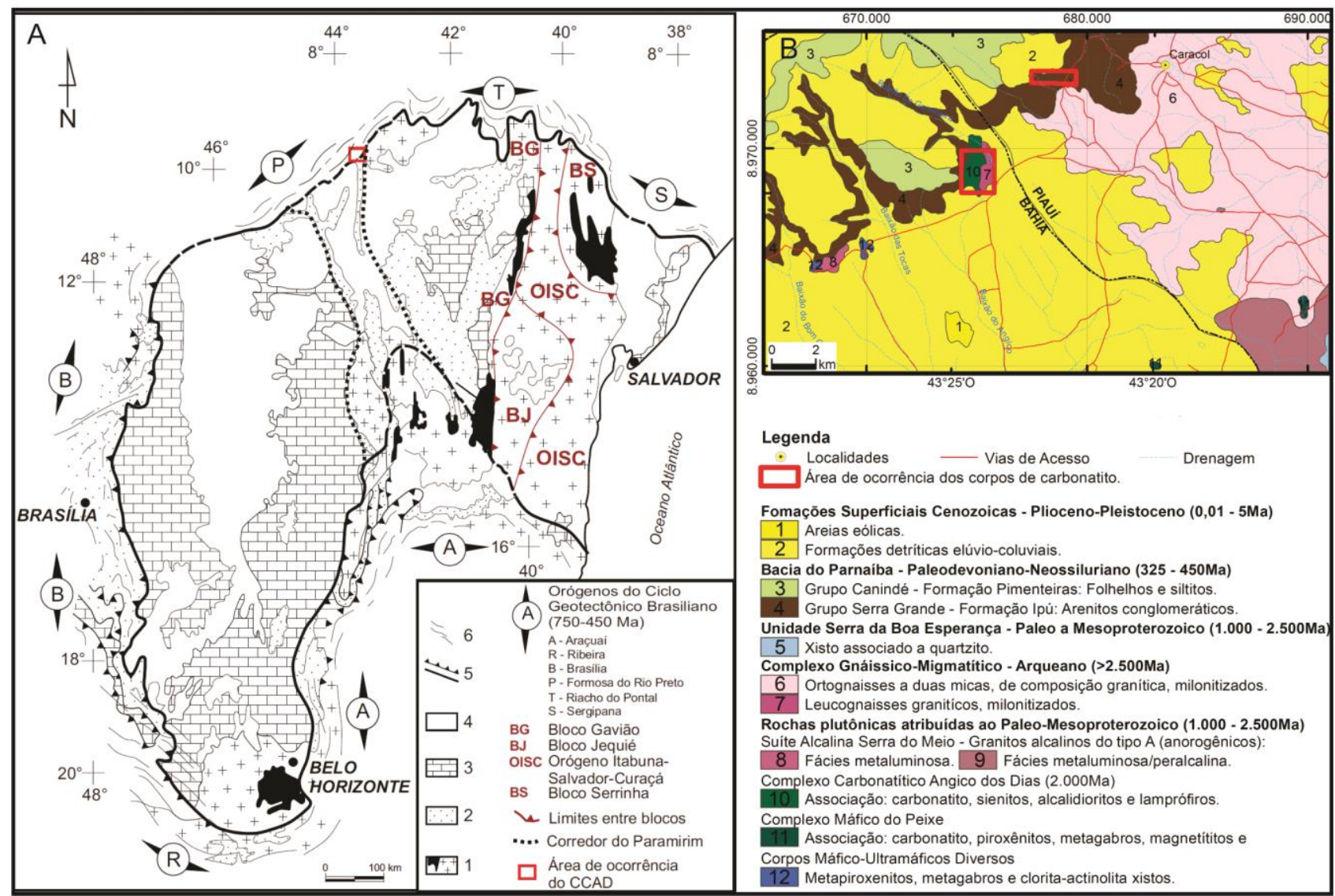

Figura 1 - A-Mapa esquemático apresentando os limites e as maiores unidades estruturais do Cráton São Francisco. BMapa Geológico Regional com as rochas do Complexo Metacarbonatítico Angico dos Dias.

Legenda: (A) Mapa esquemático apresentando os limites e as maiores unidades estruturais do Cráton São Francisco (A-Faixa Araçuá, R-Faixa Ribeira, B-Faixa Brasília, P-Faixa Formosa do Rio Preto, T-Faixa Riacho do Pontal e SFaixa Sergipana). (B) Mapa Geológico com as localizações das rochas metacarbonatíticas. Fonte: Mod. de Alkmim et al. (1993), Leite (1997) e Souza (2013).

Especificamente, a literatura com a abordagem e a caracterização dos aspectos geológicos das rochas metacarbonatíticas de Angico dos Dias é bastante restrita, resumida a Silva et al. (1987; 1988; 1999); Lapin et al. (1999) e Antonini et al. (2003).

Silva et al. (1987) classificam as rochas como metacarbonatito e/ou metasovito, devido à natureza calcítica dos carbonatos, e possuem na sua constituição mineralógica principal, apatita, olivina serpentinizada, flogopita e magnetita, além da calcita. As rochas associadas ao complexo carbonático são constituídas predominantemente por sienitos, que ocorrem lateralmente aos carbonatitos e subordinadamente por piroxenitos, álcali dioritos e lamprófiros, comumente gnaissificados e/ou milonitizados; por vezes exibem texturas ígneas originais (Silva et al., 1988).

Lapin et al. (1999) expuseram uma síntese sobre carbonatitos lineares de cinturões móveis e descreveram os traços mais gerais dos dois carbonatitos lineares mais bem estudados no mundo, Zona Linear Carbonatítico-Fenítica Tatarskaya (Rússia) e Zona de Carbonatitos de Chernigov (Ucrânia). Definem o Complexo Carbonatítico Angico dos Dias como o único do gênero conhecido no Brasil, constituindo rochas intrusivas carbonatíticas em estreitas faixas alongadas, orientadas preferencialmente para direção NE-SW e controladas por falhas profundas. A composição das rochas é relativamente simples, com minerais formados em um estágio e pertencentes a uma só fácies de temperatura. São constituídos por calciocarbonatitos e/ou metassovitos, cuja assembleia de minerais é formada por calcita (predomina), dolomita, apatita verde clara, biotita e magnetita e pseudomorfos de olivina serpentinizada.

Lateralmente ao corpo carbonatítico, Lapin et al. (1999) identificam uma zoneografia dos metassienitos e sugerem que não se trata de uma sequência de rochas magmáticas 
intrusivas, mas sim, de fenitos reomórficos e metassomáticos, produzidos pela ação do magma carbonatítico de alta temperatura, rico em sódio e voláteis, sobre milonito-gnaisses leucocráticos.

Assim, a fácies proximal é representada por uma rocha mista de carbonato e albita (biotitacalcita albititos), constituída de calcita, albita, biotita, apatita e outros minerais. A fácies intermediária é formada por albititos com textura granoblástica ou granoblástica em mosaico, nos quais ao lado da albita (albitaoligoclásio) como minerais majoritários aparecem biotita, calcita, clinopiroxênio e apatita. A fácies distal pode estar representada por quartzo sienito com textura cataclástica, nos quais ao lado da albita e do quartzo, que são os minerais predominantes, ocorrem biotita (orientada), feldspato potássico, sericita, carbonato e tremolita- actinolita.

Antonini et al. (2003) apresentam uma abordagem do tratamento isotópico destas rochas e confirmam a origem mantélica das rochas carbonatíticas, sugerindo que $o$ enriquecimento em ${ }^{18} \mathrm{O}$ é reflexo do reequilíbrio durante o metamorfismo (fácies xisto-verde) e/ou hidrotermalismo. Apresentam o mapa geológico da área das rochas metacarbonatíticas de Angico dos Dias, Bahia, a partir de pequenas mudanças propostas no trabalho inicial de Silva et al. (1987) e Lapin et al. (1999) (Figura 2).

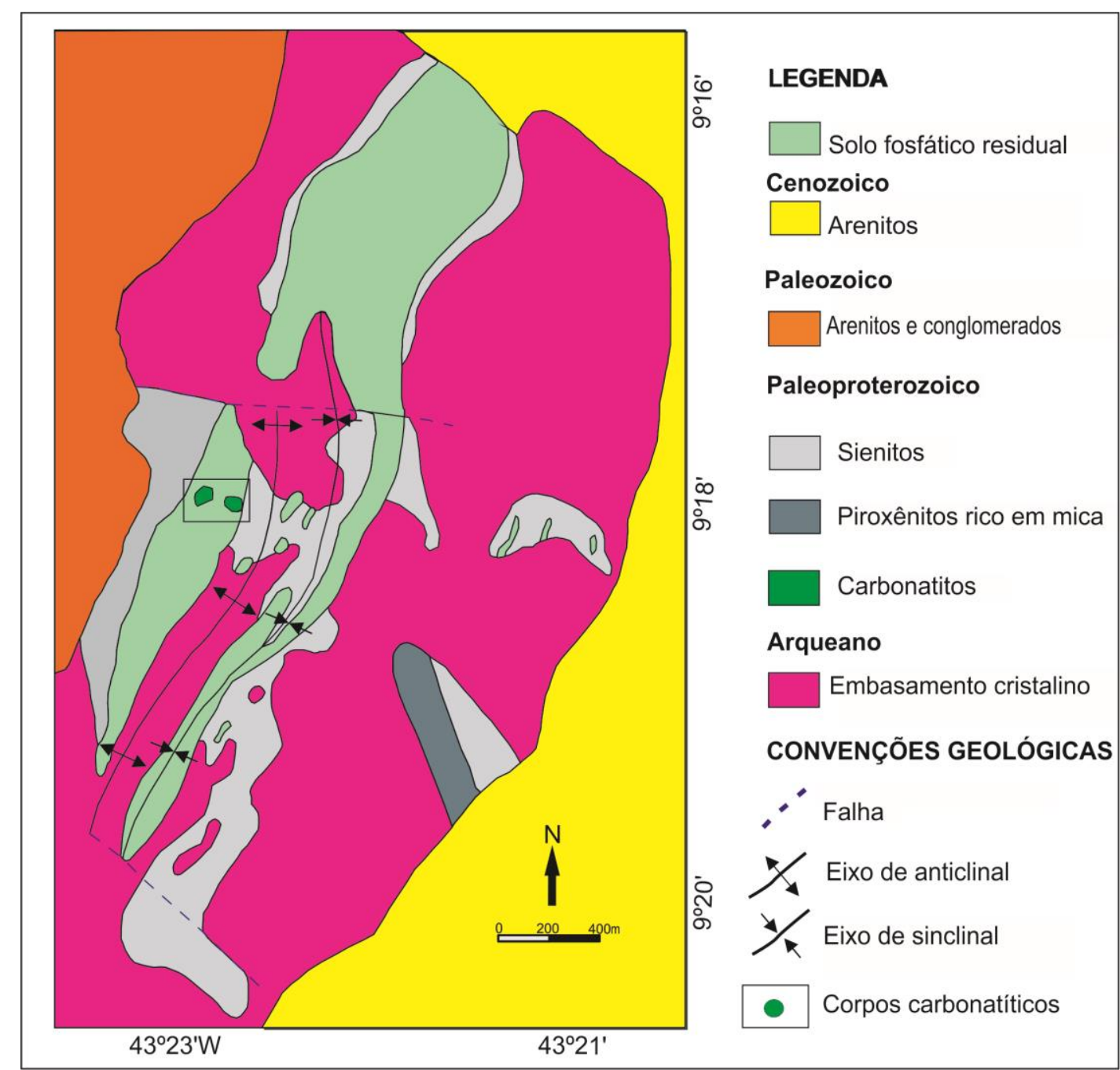

Figura 2 - Mapa Geológico da área do corpo de metacarbonatito de Angico dos Dias, BA. Fonte: Adaptado de Antonini et al. (2003), Lapin et al. (1999) e Silva et al. (1988)

\section{GEOLOGIA DAS ROCHAS METACARBONATÍTICAS}

As rochas do Complexo Metacarbonatítico de Angico dos Dias constituem uma associação paleoproterozoica composta predominantemente por metacarbonatitos (olivina-apatita 
metassovito, biotita-apatita metassovito e magnetita-olivina-apatita metassovito), expressivos metassienitos (variando entre metaalbititos, álcali feldspato metassienitos e quartzo metassienitos) e, secundariamente, podem ocorrer metapiroxenitos, metadioritos, tremolititos e metalamprófiros. Este conjunto magmático é deformado e metamorfizado regionalmente, mas quando localizados em zonas de cisalhamento, exibem predominantemente a direção da deformação milonítica.

As rochas deste complexo são intrusivas em rochas gnáissicas migmatíticas de idade arqueana-paleoproterozoicas do Complexo Sobradinho-Remanso, constituído por ortognaisses graníticos, gnaisses migmatíticos de composição tonalíticas- granodioríticastrondhjemítica (TTG) e gnaisses graníticos e anfibolíticos milonítizados. Este conjunto de rochas definem o embasamento das rochas metassedimentares das faixas móveis brasilianas Formosa Rio Preto e Riacho do Pontal.

O conjunto magmático apresenta localmente, transformações metassomáticas de fenitização e, mais abrangente, o processo de silicificação. Além disso, exibe manto intempérico, de espessura variável, que em associação às rochas carbonáticas resultam no minério de fosfato residual denominado de apatitito.

As rochas metassieníticas ocupam faixas alongadas e estreitas intrusivas em rochas do Complexo Sobradinho-Remanso. Estes corpos possuem uma morfologia tabular, por vezes lenticulares, orientados e controlados por falhas de direção NE-SW que contornam os dois principais corpos de rochas metacarbonatíticas. Às vezes é possível individualizar um zoneamento gradual dos diversos tipos de rochas metassieníticas (albitito, álcali feldspato sienito e quartzo sienito). O contato com o carbonatito é difuso e nele ocorrem com frequência zonas de biotitização decimétricas metassomáticas.

Silva et al. (1988) sugerem uma origem magmática intrusiva para o conjunto de rochas sieníticas e de forma geral, observam-se litotipos rochosos mais enriquecidos em albita (albitito) nas proximidades dos litotipos metacarbonatíticos, mais enriquecidos em feldspato potássico e quartzo (quartzo metassienito) ao distanciar-se do mesmo.

Uma visão distinta para as rochas sieníticas é apresentada por Lapin et al. (1999) que classificam as rochas como metacarbonatitos lineares que se alojam em zonas de falha, envolto por possantes auréolas zonadas de metassomatitos alcalinos (fenitos), produzidos pela ação do magma carbonatítico de alta temperatura, rico em sódio e voláteis, sobre o Complexo Sobradinho-Remanso.

Os metapiroxenitos são encontrados na forma de um corpo de tamanho expressivo e em dimensões relativamente pequenas na área, expressando corpos de dimensões que variam de centimétricas a métricas. São corpos lenticulares intrusivos no Complexo Sobradinho-Remanso e aparentemente estão associados de forma concordantemente com os metassienitos e metacarbonatitos e geralmente ocorrem como pequenos corpos associados a processos de diferenciação magmática a partir de estruturas cumuláticas. Verifica-se ainda, na região da Fazenda Pimenteira, como resultado de metamorfismo de diopsiditos, a ocorrência de blocos de rocha constituída essencialmente por tremolita, os tremolititos.

As rochas metadioríticas alcalinas apresentam-se foliadas e bandadas, de cor esbranquiçada com porções preta e verde; ocorrem em concentrações pequenas no Complexo Sobradinho-Remanso e estão associadas de forma concordante com os metassienitos e metacarbonatitos. Os diques apresentam composições dominantemente lamprofíricas alcalinas e ocorrem em praticamente todos os maciços, são quase sempre de dimensões reduzidas.

Os metacarbonatitos dispõem-se em dois conjuntos de corpos com os direitos minerários pertencentes à Mineração Galvani e à Companhia Baiana de Pesquisa Mineral. O corpo secundário de expressão exposta mais restrita encontra-se localizado ao norte da lavra, nas proximidades da Fazenda Pimenteira (Figura 3A) e o corpo principal está localizado na mina de fosfato da Mineração Galvani (Figura 3B).

As reais dimensões das rochas metacarbonatíticas ainda são desconhecidas, pois a norte e noroeste elas se acham recobertas por chapadões de arenitos e conglomerado com escarpas abruptas de rochas sedimentares de idade terciária-quaternária que muitas vezes dificultam as correlações e interpretações estratigráficas e estruturais (Figura 4A). 

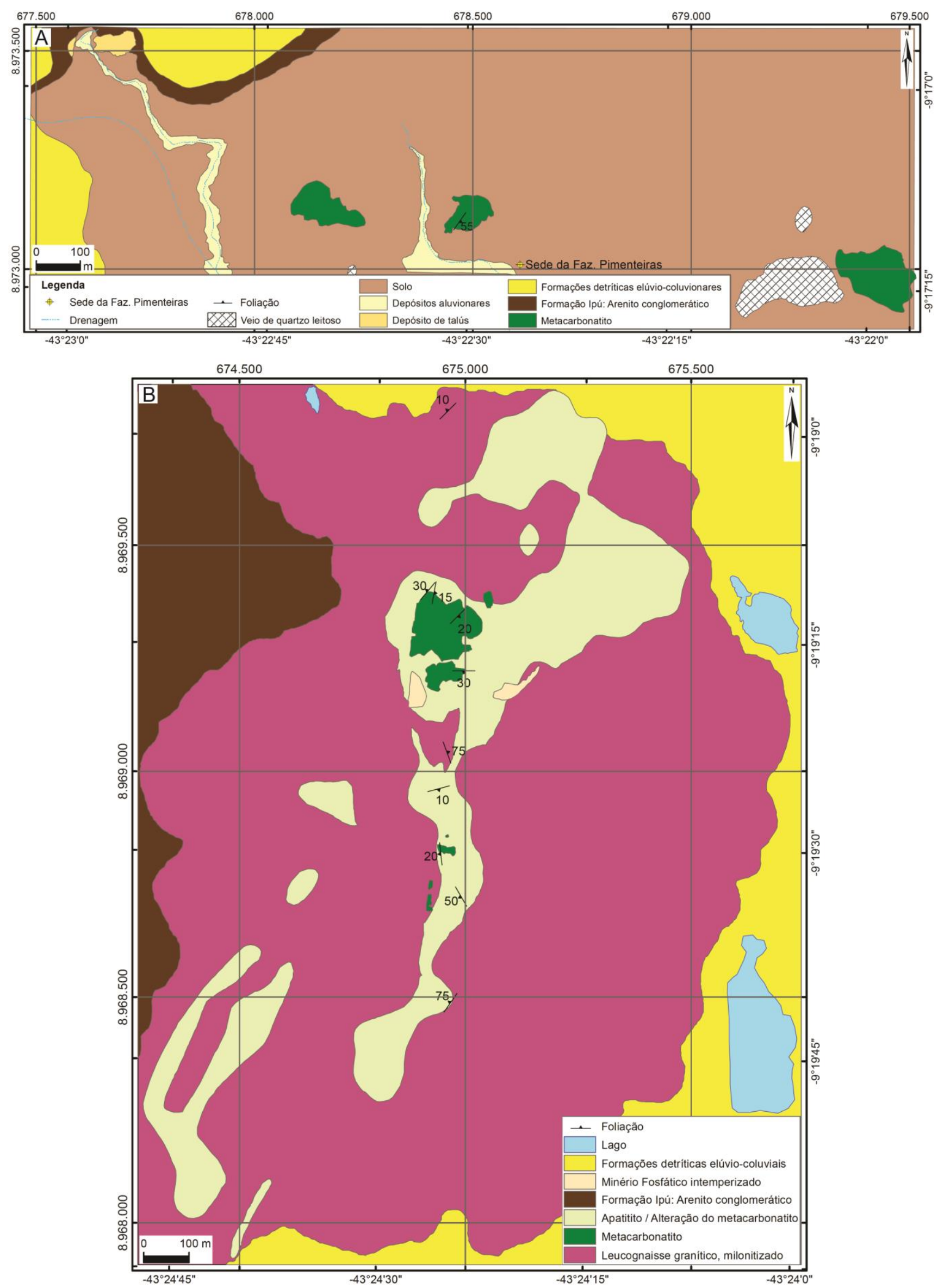

Figura 3 - A) Mapa geológico com a localização das rochas metacarbonatíticas da região da Fazenda Pimenteiras. B) Mapa geológico da região da mina de fosfato da Mineração Galvani. Fonte: (Luciano 2016, Mod. de Galvani, 2013). 

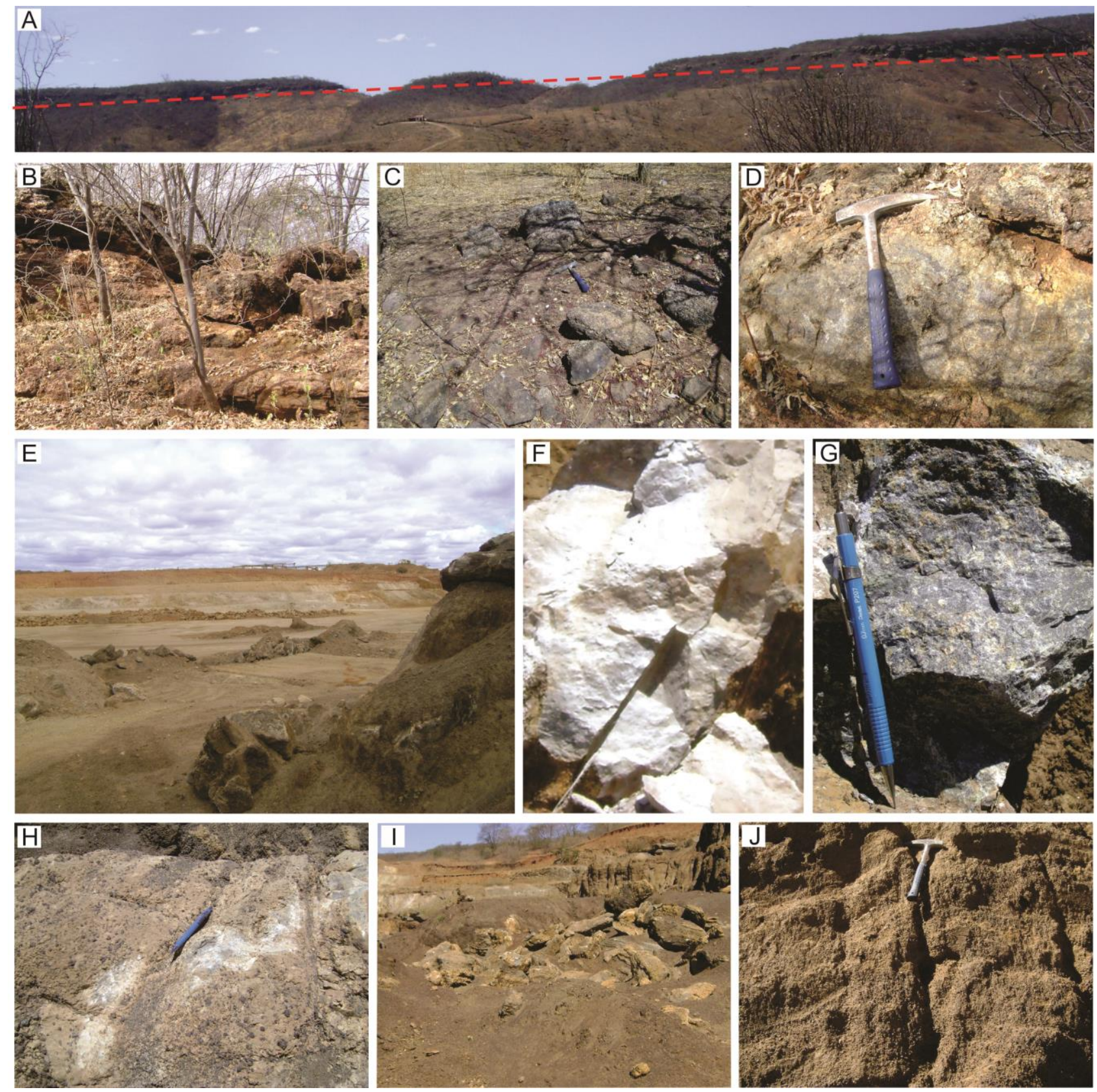

Figura 4 - Prancha fotográfica apresentando afloramentos das rochas metacarbonatíticas. A) Vista panorâmica com visada para norte em que se observam litotipos da Bacia do Parnaíba recobrindo rochas mais antigas. B, C e D) Afloramento e blocos de metacarbonatito silicificado em topos de pequenos morros, nos arredores da faz. Pimenteiras. E) Vista panorâmica da mina de fosfato associado aos corpos de rocha metacarbonatíticas, distrito de Angico dos Dias. (F e G) Fotografias de detalhe de duas faciologias distintas observadas em afloramentos dentro da mina de fosfato: metacarbonatito e apatita-flogopita-olivina metacarbonatito, respectivamente. H) Afloramento de olivina-apatita metacarbonatito dentro da mina de fosfato da Galvani. I e J) Manto de intemperismo que constitui o depósito de fosfato residual (apatitito) da mina de fosfato da Galvani.

O conjunto situado a nordeste da lavra, localizado na Fazenda Pimenteira, é composto por pequenos afloramentos com dimensões que variam entre $120 \mathrm{~m}$ e $200 \mathrm{~m}$ de comprimento e $100 \mathrm{~m}$ a $190 \mathrm{~m}$ de largura, geralmente expostos na superfície como pequenos afloramentos ou como inúmeros agregados de blocos, constituindo topos de pequenas elevações. Estes tipos de ocorrências são resultados das rochas carbonatíticas quando se encontram parcialmente silicificadas (Figura 4B, C, D), aumentando a sua resistência ao intemperismo. Lateralmente, a este tipo de ocorrência de agregado de blocos, não se evidenciam as rochas carbonatíticas, que facilmente resultam num manto de intemperismo.

O conjunto principal encontra-se na lavra da mina a céu aberto de fosfato da Mineradora Galvani (Figura 4E), apresentando-se regionalmente sob forma alongada segundo a 
direção NNE e separado em pequenos corpos. Os corpos de rochas constituem carbonatitos orientados linearmente, que se alojam em zonas de falhas; apresentam disposição concordante em relação às rochas encaixantes e mantêm direção paralela à estruturação geral milonítica.

Os corpos de rocha metacarbonatítica localizados na mineração Galvani apresentam tamanhos distintos e expõem-se ao longo de $514 \mathrm{~m}$ de comprimento. Nas porções sul e central, exibem-se sob forma delgada, com larguras em torno de $17 \mathrm{~m}$ e $29 \mathrm{~m}$, enquanto na porção norte se alargam atingindo cerca de $108 \mathrm{~m}$.

Silva et al. (1988) descrevem as rochas do complexo segunda direção regional N20E, com dimensão em planta superior a $2250 \mathrm{~m}$, largura aparente mínima de $1250 \mathrm{~m}$ e espessura maior que $50 \mathrm{~m}$.

Lapin et al. (1999) descrevem o corpo carbonatítico principal constituído por dois corpos principais com direção geral N20E/45NW. O menor, em forma de lente, situado a oeste, com cerca de $960 \mathrm{~m}$ de comprimento e, ao redor de $180 \mathrm{~m}$ na sua parte mais larga. O maior, localizado a leste, é delgado na sua porção sul e central, com larguras aparentes variando de 53 a $95 \mathrm{~m}$ e na porção norte o corpo alarga-se atingindo cerca de $360 \mathrm{~m}$ e, expõe-se ao longo de $2070 \mathrm{~m}$

As rochas são classificadas principalmente como apatita sovito e/ou calciocarbonatito, granulação média a grossa, coloração variando de cinza claro a branco (Figura 4F, G) e, são constituídas necessariamente pela presença dominante de calcita e apatita, além de dolomita, olivina, flogopita, biotita, magnetita e serpentina.

As concentrações de apatita são responsáveis pela formação de dois tipos de jazimentos fosfáticos, o primário, representado por apatita sovitos, e o secundário, mais enriquecido em apatita, formado por processos de alteração supergênica.

Os depósitos primários são originados por processos magmáticos de cristalização fracionada, por segregação gravitacional identificado pela presença de níveis ou bandamento composicional entre as variedades de rochas metacarbonatíticas. Os níveis estão diferenciados principalmente pela presença mais enriquecida de apatita, minerais ferromagnesiano e magnetita, definindo um bandamento magmático cumulático, que constitui o principal mecanismo responsável pela evolução do magma, a cristalização fracionada, por segregação gravítica, de caráter estratiforme, resultando da flutuação dos félsicos (carbonatos) e segregação de cumulatos (minerais ferro-magnesianos e magnetita), permitindo assim a geração de variados litotipos de carbonatitos de rochas ultrabásicas.

Algumas das variedades de rochas metacarbonatíticas apresentam-se enriquecidas em minerais ferro-magnesianos e magnetita, definindo feições ortocumuláticas que podem ocorrer sob a forma disseminada ou constituindo feições de acamamento e/ou bandamento, podendo atingir porcentagens acima de $10 \%$ de magnetita (Figura $4 \mathrm{H}$ ).

Os depósitos secundários e/ou residuais formam-se por processos supergênicos atuantes que geraram manto de intemperismo instalado sobre o carbonatito que deu origem a importante depósito de fosfato residual (apatitito), observado no corpo principal o desenvolvimento de uma crosta fosfática, cuja espessura atinge $25 \mathrm{~m}$, tendo em média $10 \mathrm{~m}$, podendo conservar ou não seus aspectos estruturais (Figura 4I, J).

O apatitito é constituído predominantemente pela apatita de granulometria grossa e subordinadamente por argilominerais e óxidos de ferro. A preservação de apatita no minério residual se deve a sua maior estabilidade, em relação ao carbonato, perante os processos intempéricos existentes. Eventualmente, junto à superfície, pode-se ter carapaças ferruginosas descontínuas, hoje representadas por campos de blocos de algumas dezenas de metros quadrados de material cimentado por óxidos de ferro e, por vezes, silicificado.

Os corpos de rochas metacarbonatíticas apresentam faciologias distintas e permitem individualizar cinco fácies petrográficas principais com contatos graduais entre si (Luciano, 2016). São elas: metacarbonatito; olivina-apatita metacarbonatito; apatitaflogopita-olivina metacarbonatito; olivinaapatita-biotita/flogopita metacarbonatito; metacarbonatito silicificado. 


\section{ASPECTOS DEFORMACIONAIS}

A evolução das rochas metacarbonatíticas apresenta um registro dominantemente paleoproterozoico e, posteriormente superimpostos, associam-se eventos de uma tectônica colisional neoproterozoica constituída inicialmente por movimentos crustais convergentes, a partir de eventos tectônicos tangenciais e consequente espessamento de massas crustais. Durante a finalização do processo colisional, ocorreu uma tectônica de descompressão e o consequente evento tectônico transcorrente final. Esta tectônica é superposta a todas as unidades litoestratigráficas arqueanas e proterozóicas.

As rochas metacarbonatíticas encontram-se encaixadas em rochas do embasamento de idade arqueana constituídas por ortognaisses graníticos, gnaisses migmatíticos de composição tonalíticasgranodioríticas-trondhjemítica (TTG).

As estruturas mais antigas em Angico dos Dias encontram-se caracterizadas nas rochas do embasamento cristalino, de idade arqueanapaleoproterozoica e, registram evidência de no mínimo duas fases deformacionais anteriores à intrusão, $D_{n-2}$ e $D_{n-1}$.

O padrão de deformação é caracterizado em rochas migmatíticas apresentando redobramento e, caracterizado pela presença de dobramento $\mathrm{D}_{\mathrm{n}-1}$ contendo dobras intrafoliais, parasíticas e dobras rompidas da deformação $\mathrm{D}_{\mathrm{n}-2}$. No processo de migmatização observa-se o dobramento de um conjunto mineral metamórfico anterior, observados por anfibólios e biotitas, definindo uma foliação anterior $\mathrm{S}_{\mathrm{n}-3}$.

A feição deformacional antiga de idade arqueana-paleoproterozoica, mais preservada nas rochas do embasamento gnáissico migmatítico é uma foliação definida por um bandamento gnáissico $\mathrm{S}_{\mathrm{n}-2}$, que se orienta para norte, com mergulhos para $\mathrm{E}$ e W.

O dobramento é caracterizado por dobras assimétricas apresentando planos axiais verticalizados. Superimposto a esse bandamento, registra-se uma forte foliação milonítica $\mathrm{S}_{\mathrm{n}-1}$ com trend deformacional na direção preferencial NE-SW, caracterizando antigas zonas de cisalhamento. Localmente, impõem-se aos migmatitos e granitoides o caráter de milonito a blastomilonitos gnaisses e em ultramilonitos o caráter de filonitizado.
A foliação $S_{n-1}$ é afetada por dobramento cuja direção em NE-SW, orientada regionalmente para $\mathrm{N} 30 \mathrm{E}$ e $\mathrm{N} 40 \mathrm{E}$, com mergulhos para NW e o eixo de transporte tectônico é de NW para SE (Silva et al., 1987).

As feições metamórficas $\mathrm{M}_{-2}$ e $\mathrm{M}_{-1}$, quando preservadas, encontram-se identificadas em $\mathrm{M}_{-2}$ pelo processo de migmatização, em fácies anfibolito alta e apresentam-se identificadas em $\mathrm{M}_{-1}$ pelo caráter milonítico, paragêneses superimpostas retrometamórficas.

Em ambiente de uma crosta rígida continental paleoproterozoica, a partir de mecanismos gerados por plumas mantélicas, de domeamento crustal e distensivos de rifteamento, apresentam-se o emplacement e a cristalização do magma carbonatítico. Nesta fase, desenvolvem-se as estruturas primárias presentes nas rochas carbonatíticas, o bandamento reliquiar. Localmente, o acamamento é preservado, constituído por um bandamento composicional originado por segregação gravítica, de caráter estratiforme (Figura 5A).

Nestas situações preservam-se mais nitidamente outras feições texturais reliquiares magmáticas. Devido aos processos de transposição deformacionais neoproterozoicos, este bandamento se mantém de forma escassa somente nas áreas menos deformadas.

Associados aos processos tardi magmáticos ocorrem as frequentes transformações caracterizadas nos processos de albitização, sericitização/moscovitização, biotitização, saussuritização, cloritização e epidotização, que resultam em alterações metamórficas, refletindo a ação intensa de fluídos hidrotermais (Figura 5B).

A atual estruturação tectônico-metamórfica de toda a região e, consequentemente nas rochas metacarbonatíticas, passa pelo arranjo tectônico neoproterozoico, superimposto à deformação das faixas Formosa do Rio Preto e Riacho do Pontal. O padrão deformacional meso a neoproterozóico descrito para as rochas metacarbonatíticas é evidenciado pelo registro de pelo menos três fases deformacionais que afetam as rochas do embasamento gnáissico migmatítico (Complexo Remanso-Sobradinho), as rochas do Complexo Angico dos Dias e as rochas metassedimentares das faixas Formosa do Rio Preto e Riacho do Pontal. 

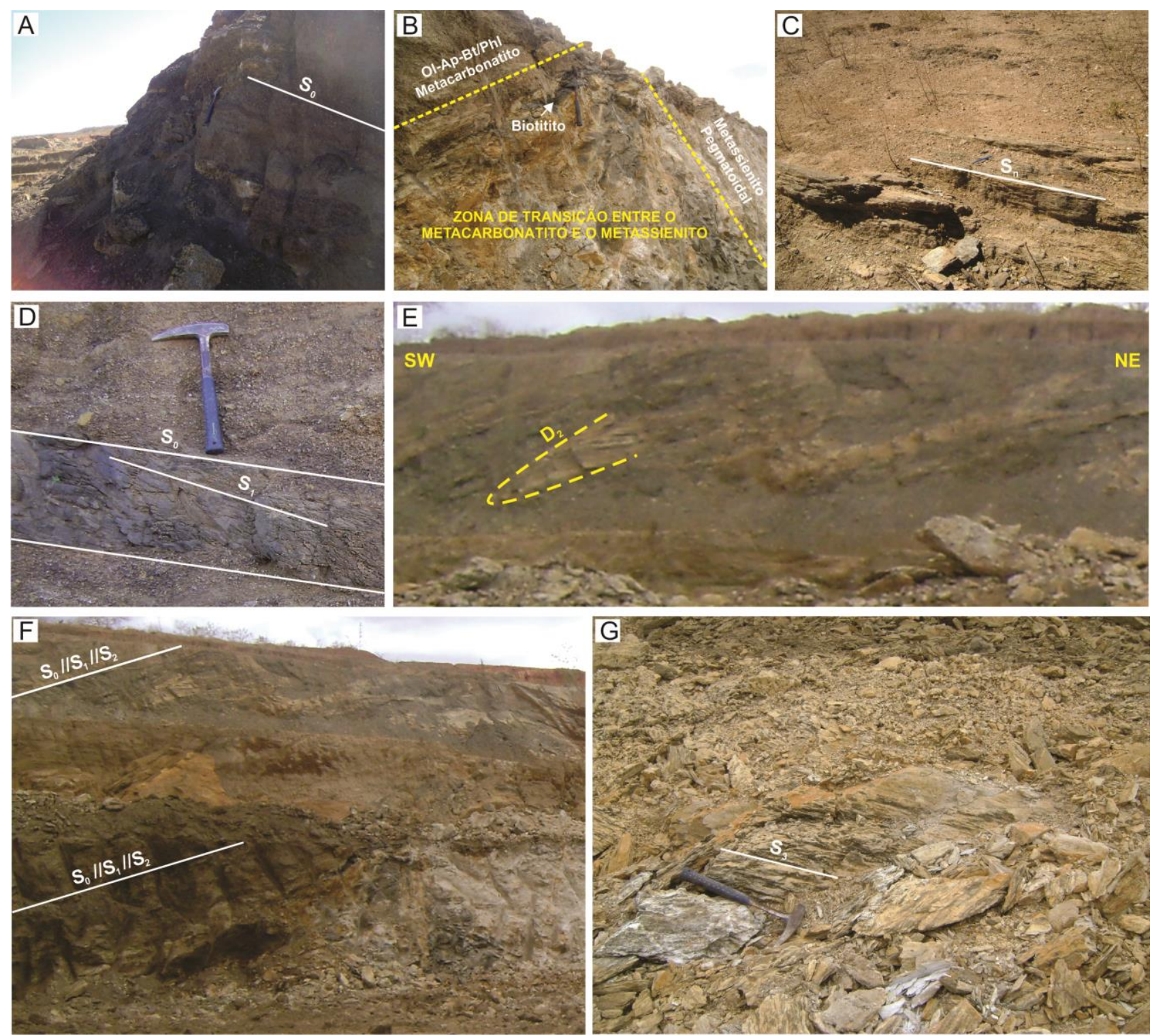

Figura 5 - Prancha fotográfica apresentando aspectos estruturais de afloramento das rochas metacarbonatíticas . A) Rochas metacarbonatíticas apresentando acamadamento cumulático e/ou bandamento composicional $\mathrm{S}_{0}$ magmático paleoproterozoico. B) Zona de contato entre as rochas metassieníticas e, as rochas metacarbonatíticas, localizada na mina Galvani. (C) Rochas do embasamento cristalino $\mathrm{S}_{0}$ superimposto foliação plano-axial $\mathrm{S}_{\mathrm{n}}$. D) Bandamento composicional em rochas metacarbonatíticas, $S_{0}$ discordante a foliação plano-axial $S_{1}$. E) Dobramentos regionais inversos ou recumbentes associados às zonas de cavalgamento $\mathrm{D}_{2}$. F) Zonas de cavalgamento resultando nas superfícies $\mathrm{S}_{0} / / \mathrm{S}_{1}$ paralelizada a foliação $\mathrm{S}_{2}$. G) Foliação milonítica $\mathrm{S}_{3}$.

As estruturas primárias $\mathrm{S}_{0}$ de idade paleoproterozóica são representadas nas rochas carbonatíticas (Figura 5A) por um acamamento reliquiar magmático, enquanto nas rochas metassedimentares corresponderia ao acamamento sedimentar (Figura 5C).

O quadro estrutural-metamórfico neoproterozóico é identificado por três fases deformacionais, designadas como $D_{n}, D_{n+1}$, $\mathrm{D}_{\mathrm{n}+2}$. As deformações progressivas tangenciais encontram-se associadas ao início do processo colisional, com formação de dobras isoclinais invertidas a recumbentes da fase $D_{n}$, marcada por uma clivagem ardosiana ou xistosidade plano-axial $S_{n}$ com atitude N40E/18NW (Figura 5D) e, nos flancos dos dobramentos, esta foliação é dominantemente paralela à subparalela a $\mathrm{S}_{0}$.

Uma clivagem ardosiana $S_{n+1}$ com plano axial de baixo ângulo foi identificada e é definida por redobramentos assimétricos, que produz uma foliação com atitude N60E/20SE, apresentando direção muito próxima a $\mathrm{S}_{\mathrm{n}}$. Constitui a fase mais importante no rearranjo tectônico, sendo responsável pelo desenho dos dobramentos regionais, que invariavelmente são inversos ou recumbentes e associam-se às zonas de cavalgamento. No entanto, quando 
paralelizadas à superfície anterior, apenas a foliação $S_{n+1}$ é preservada (Figura 5E e F).

A fase $D_{n+2}$, de caráter dúctil-rúptil, é definida pela formação de dobras suaves a abertas da foliação $S_{n+1}$, constituindo sinformais e antiformais, sanfonadas de eixo sub-horizontal, e mergulhos variando para NW e SE, com uma tênue clivagem subvertical, com plano axial de atitude NW-SE. Com rompimentos de flancos e charneiras das dobras anteriormente formadas, evolui gradativamente e localmente para zonas de cisalhamento, definindo uma foliação $S_{n+2}$. A foliação $S_{n+2}$ é penetrativa nas zonas de cisalhamento, caracterizando-se como uma foliação milonítica (Figura 5G) associada à zona de cisalhamento transcorrente e, com a geração de filonitos e desenvolvimento de um bandamento tectônico, que oblitera as estruturas planares e reliquiares anteriores. Sugere-se uma superposição de eventos deformacionais, com reativação de falhamentos ao longo do tempo geológico.

Hasui (1988) com base em informações gravimétricas regionais, indicou a existência de uma sutura crustal com a direção NE, que passa na região de Campo Alegre de Lourdes, relacionada à tectônica convergente, envolvendo aproximação e colisão de massas continentais.

As paragêneses metamórficas neoproterozoicas $\mathrm{Mn}, \mathrm{Mn}+1$, caracterizam-se por associações minerais em fácies xisto-verde média-alta, observadas nas rochas metassedimentares, enquanto o metamorfismo $\mathrm{Mn}+2$ é claramente retrometamórfico para xisto verde baixo.

As paragêneses ígneas anidras e de altas temperaturas sofrem consequentemente a desestabilização minerais por hidratação, em condições metamórficas mais brandas, e a consequente geração de minerais de alterações.

Frequentemente as transformações em minerais hidratados é total, mas podem preservar pseudomorfos, principalmente de olivina e piroxênio. Os pseudomorfos de piroxênios e/ou hornblenda apresentam o desenvolvimento de tremolita-actinolita e clorita $e$ as olivinas estão fortemente serpentinizadas. São frequentes ainda como minerais secundários epidoto, sericita/ moscovita, clorita e carbonatos.

As rochas intrusivas metacarbonatíticas se distribuem em dois corpos que ocorrem em estreitas faixas alongadas, orientadas N20E e que foram reativadas ao longo de zonas de cisalhamento.

Sugere-se o emplacement magmático das rochas metacarbonáticas associado à fase inicial, na forma de um corpo tabular subvertical, alojado e associado inicialmente a falhas profundas $\mathrm{S}_{\mathrm{n}-1}$, de idade paleoproterozóicas, em rochas encaixantes já dobradas em isoclinais com eixos de direção NS (Silva et. al., 1987). Na fase final, as rochas foram submetidas às deformações $S_{n+2}$ de eixo de direção NE-SW, de idade neoproterozoica, controlando a forma e disposição final dos corpos. Os metacarbonatitos ocorrem na forma de dois corpos com direção geral N20E e mergulhos predominantes para NW, com ângulos inferiores a $45^{\circ}$.

As formas lenticulares dos corpos de minério da jazida foram originadas por cisalhamentos tangenciais e transcorrentes, com eixo de transporte tectônico de NW para SE. Esta lenticularidade dos corpos é produto final da tectônica compressiva neoproterozoica superimposta pelas faixas de Dobramento Formosa do Rio Preto e Riacho do Pontal.

\section{CONCLUSÕES}

O Complexo Metacarbonatítico Angico dos Dias é constituído dominantemente por corpos magmáticos de metacarbonatitos, metassienitos variados e metapiroxenitos, raros metadioritos alcalinos e tremolititos, além de dique diversos de metalamprófiros.

O conjunto magmático apresenta localmente, transformações metassomáticas de fenitização e, mais abrangente o processo de silicificação. Um espesso manto de intemperismo, proveniente da alteração dos metacarbonatitos, concentra-se sobre as rochas metacarbonatíticas, constituindo um importante depósito de fosfato residual denominado de apatitito.

As rochas são classificadas dominantemente como calciocarbonatito constituído principalmente por calcita e apatita e subordinado dolomita, olivina, flogopita e magnetita e, a variação no conteúdo de apatita, minerais ferromagnesianos e magnetita, constituem um 
acamamento magmático cumulático, que permite individualizar vários litotipos petrográficos e constitui o principal mecanismo responsável pela evolução do magma.

A evolução das rochas metacarbonatíticas encontra-se inicialmente associada às plumas mantélicas e a partir de mecanismos distensivos de rifteamento ou domeamento crustal de uma crosta arqueana, constituída por ortognaisses graníticos, gnaisses migmatíticos de composição tonalíticas - granodioríticas -trondhjemítica (TTG) do Complexo Sobradinho-Remanso, há consequente geração e emplacement dos carbonatitos e posteriormente uma tectônica colisional apresentando registro geocronológico dominantemente neoproterozoico.

As estruturas mais antigas em Angico dos Dias encontram-se caracterizadas nas rochas do embasamento cristalino, de idade arqueanapaleoproterozoica e, registram evidência de no mínimo duas fases deformacionais anteriores $D_{n-2}$ e $D_{n-1}$. No processo de migmatização observa-se o dobramento de um conjunto mineral metamórfico anterior, observados por anfibólios e biotitas, definindo uma foliação anterior $\mathrm{S}_{\mathrm{n}-3}$.

As feições metamórficas $\mathrm{M}_{-2}$ e $\mathrm{M}_{-1}$, quando preservadas, encontram-se identificadas em fácies anfibolito alta $\mathrm{M}_{-2}$, evidenciadas por um processo de migmatização e $\mathrm{M}_{-1}$ de caráter milonítico, paragêneses superimpostas retrometamórficas.

Superimposto às rochas do embasamento, associado a uma tectônica colisional neoproterozoica e, a partir de eventos tectônicos tangenciais e consequente espessamento de massas crustais, tem-se a formação das faixas móveis Formosa do Rio Preto e Riacho do Pontal. A finalização do processo colisional é marcada por um evento tectônico transcorrente. Esta tectônica é superposta a todas as unidades litoestratigráficas arqueanas e proterozoicas.

Associados aos processos tardi-magmáticos ocorrem as frequentes transformações caracterizadas nos processos de albitização, sericitização/muscovitização, saussuritização, cloritização e epidotização, que resultam em alterações metamórficas, refletindo a ação intensa de fluídos hidrotermais.

A atual estruturação tectônico-metamórfica de toda a região e, consequentemente, nas rochas metacarbonatíticas, passa pelo arranjo tectônico neoproterozoico, superimposto da deformação das faixas móveis Formosa do Rio Preto e Riacho do Pontal.

O padrão deformacional meso a neoproterozoico é evidenciado pelo registro de pelo menos três fases deformacionais, que afetam as rochas do embasamento gnáissico migmatítico (Complexo Remanso - Sobradinho), as rochas do Complexo Angico dos Dias e as rochas metassedimentares das faixas Formosa Rio Preto e Riacho do Pontal.

As paragêneses metamórficas neoproterozoicas $\mathbf{M}_{\mathrm{n}}$ e $\mathbf{M}_{\mathrm{n}+1}$ caracterizam-se por associações minerais em fácies xisto-verde média-alta, observadas nas rochas metassedimentares, enquanto o metamorfismo $\mathrm{M}_{\mathrm{n}+2}$ é claramente retrometamórfico para xisto verde baixo.

As paragêneses ígneas anidras de altas temperaturas e a desestabilização destes minerais em condições metamórficas mais brandas por hidratação são acentuadas nas rochas, e consequentemente levaram à geração de novos e inúmeros minerais de alterações.

As formas lenticulares dessa jazida foram interpretadas como produto da tectônica compressiva, constituído por cisalhamento tangencial e transcorrente e, foi responsável pelo formato lenticular dos corpos do minério tendo participação de eventos do final do Neoproterozoico.

\section{AGRADECIMENTOS}

Os autores agradecem ao apoio da Companhia Baiana de Pesquisa Mineral (CBPM). Ao Programa de Pós-Graduação em Geociências e Meio Ambiente do Instituto de Geociências e Ciências Exatas da UNESP - Universidade Estadual Paulista.

\section{REFERÊNCIAS}

ALKMIM, F.F.; BRITO NEVES B.B.; ALVES J.A.C. Arcabouço tectônico do Cráton São Francisco: uma revisão. In: SIMPÓSIO SOBRE O CRÁTON SÃO FRANCISCO, 2. 1993, Salvador. Anais... Salvador: Sociedade Brasileira de Geologia, 1993, v. 1, p. 45-62.

ALMEIDA, F.F.M. de. O Cráton São Francisco. Revista Brasileira de Geociências, v. 7, n. 4, p. 349-367, 1977.
ANTONINI, P.; COMIN-CHIARAMONTI, P.; GOMES, C.B.; CENSI, P.; RIFFEL, B.F.; YAMAMOTO, E. The Early Proterozoic carbonatite complex of Angico dos Dias, Bahia State, Brazil: geochemical and Sr-Nd isotopic evidence for an enriched mantle origin. Mineralogical Magazine, v. 67, n. 5, p. 1039-1057, 2003.

BARBOSA, J.S.F. \& SABATÉ, P. Archean and 
Paleoproterozoic crust of the São Francisco Craton, Bahia, Brazil: geodynamic features. Precambrian Research, v. 133, p. 1-27, 2004.

BAUER, H.E. As minas de ferro de Jacupiranga. Revista de Engenharia, 213 p., 1877.

CALDASSO, A.L.S.; ENNES, E.R.; GRAZIA, C.A. Geologia da região sudeste do Estado do Piaú - Projeto Sudeste do Piauí 1: relatório final de geologia, Brasília, DNPM (Série Geologia 21; Seção Geologia Básica 15), 1973.

COMIN-CHIARAMONTI, P. \& GOMES, C.B. (Coordenadores). Mesozoic to Cenozoic Alkaline Magmatism in the Brazilian Platform. São Paulo: Editora da Universidade São Paulo, 750 p., 2005.

DERBY, O.A. On nepheline rocks in Brasil. Quarterly Journal, v. 7, n. 15, p. 460-467, 1891.

GALVANI. Mapa Geológico/Topográfico com localização de furos de sonda e cava. Angico dos Dias: Relatório Interno, escala 1:5.000, 2013.

HASUI, Y. Modelo estrutural de Angico dos Dias, BA, com ênfase à área de ocorrência do metacarbonatito. Relatório interno. Angico dos Dias: Companhia Brasileira de Metalurgia e Mineração, 1988.

HASUI, Y. O Cráton São Francisco. In: HASUI, Y. (Coordenador), Geologia do Brasil, Rio de Janeiro: Editora Beca, p. 201-227, 2012.

HUSSAK, E. Ueber Brazilit, ein neues tantal (niob) mineral von der Eisenmine Jacupiranga. Neues Jahrbuch für Mineralogie, v. 2, p. 141-159, 1892.

KAHN, H.; CASSOLA, M.S.; OBA, C.A.I.; LIBERAL, G.S.E.; RIFFEL, B.F. Caracterização tecnológica do minério residual de fosfato de Angico dos Dias, BA. In: ENCONTRO NACIONAL DE TRATAMENTO DE MINÉRIOS E HIDROMETALURGIA, 14, Salvador. Anais... Salvador: Associação Brasileira de Mineração, 1990, v. 1, p. 196-211.

LAPIN, A.V.; RIWANUCHI, W.; PLOSHKO, V.V. Carbonatitos lineares de cinturões móveis: uma síntese. Revista Brasileira de Geociências, v. 29, p. 483-490, 1999.

LEITE, C.M.M. \& SANTOS, R.A. Tectônica e estrutura da região de Campo Alegre de Lourdes, NNW do Estado da Bahia. In: CONGRESSO BRASILEIRO DE GEOLOGIA, 38. Camboriú. Resumos Expandidos... Camboriú: Sociedade Brasileira de Geologia, 1994, v. 1, p. 272-274.

LEITE, C.M.M. Campo Alegre de Lourdes, folha SC. 23-XD-IV. Peixe, folha SC. 23-X-D-I: Estado da Bahia. Brasília: Companhia de Pesquisa de Recursos Minerais, 158, p. 1997.

LEONARDOS, O.H. Carbonatitos com apatita e pirocloro. Ministério da Agricultura, Rio de Janeiro: Avulso, Departamento Nacional de Pesquisa Mineral v. 8, p. 7-30, 1956.

LIBERAL, G.S. \& CASSOLA, H.L. O depósito de fosfato Angico dos Dias, $\mathrm{Ba}$; geologia, beneficiamento e aproveitamento econômico. In: 3 CONGRESSO BRASILEIRO DE MINERAÇÃO. São Paulo. Instituto Brasileiro de Mineração. Coletânea de Trabalhos Técnicos, v. 2, p. 266-287, 1989.

LIMA, R.F.F.; SOARES, J.V.; SANTOS, L.M.B.; LADO, S.E. Projeto Fe-Ti de Campo Alegre de Lourdes - Fase I. Salvador: Projetos Técnicos da Companhia Baiana de Pesquisa Mineral, 1977.
LUCIANO, R.L. Petrografia e geoquímica das rochas metacarbonatíticas do Complexo Angico dos Dias, divisa Bahia/Piauí, Brasil. Rio Claro. 2016, 273 p. Tese de (Doutorado) - Instituto de Geociências e Ciências Exatas da Universidade Estadual Paulista.

MARIANO, A.N. Analytival report on rocks from Angico dos Dias. Salvador: Relatório Interno, Companhia Brasileira de Metalurgia e Mineração, 1987.

MELCHER, G.C. Carbonatito de Jacupiranga, estado de São Paulo. São Paulo, 1962, 59 p. Tese de (Doutorado)Instituto de Geociências, Universidade de São Paulo.

MORAES, A.M.V. Projeto Fe - Ti - V de Campo Alegre de Lourdes: fase III; texto e mapas. Salvador: Companhia Baiana de Pesquisa Mineral, 2006.

NEUMANN, R. \& ALCOVER, A.N. Caracterização mineralógica e tecnológica do minério fosfórico de Angico dos Dias/Caracol (BA/PI). Relatório técnico. Projeto PADCT, 1999.

SALVIANO, A.; SAMPAIO, D.R.; AZEVEDO, H.C.A.; OLIVEIRA, M.T.M. Projeto Fe-Ti de Campo Alegre de Lourdes - Fase II. Salvador: Companhia Brasileira de Metalurgia e Mineração, 1979.

SANTOS, C.N. Micromorfologia, geoquímica e aspectos tecnológicos da apatita da associação alcalinometacarbonatítica pré-cambriana de Angico dos Dias, BA. São Paulo. 2001, 131 p. Dissertação (Mestrado) - Instituto de Geociências, Universidade de São Paulo.

SILVA, A.B,; LIBERAL G.S.; ISSA FILHO, A.; RODRIGUES, C.S.; RIFFEL B.F. Depósito de fosfato em carbonatito pré-cambriano, Angico dos Dias-Ba. Sociedade Brasileira de Geologia, Núcleo da Bahia, Salvador. 15 p., 1987.

SILVA, A.B.; LIBERAL G.S.; GROSSI SAD, J.H.; ISSA FILHO, A.; RODRIGUES, C.S.; RIFFEL B.F. Geologia e petrologia do Complexo Angico dos Dias (Bahia, Brasil), uma associação metacarbonatíticas pré-cambriana. Geochimica Brasiliensis, v. 2, n. 1, p. 81-108, 1988.

SILVA, A.B.; LIBERAL, G.S.; RIFFEL, B.F.; ISSA FILHO, A. Depósito de fosfato de Angico dos Dias, Campo Alegre de Lourdes, Bahia. Brasília: Principais Depósitos Minerais do Brasil, Departamento Nacional de Produção Mineral. V-4C, p. 123-130, 1997.

SILVEROL, A.C. Processo Humifert para fertilizantes alternativos organo-fosfatados: obtenção a partir do minério de Angico dos Dias, caracterização dos compostos e avaliação da eficiência agronômica. São Paulo, 2006, 179 p. Dissertação (Mestrado) - Instituto de Geociências, Universidade de São Paulo.

SOUZA, F.R. Peixe - Folha SC.23-X-D-I: Estado do Piauí. Carta Geológica. Teresina: Companhia de Pesquisa de Recursos Minerais, escala 1:100.000. Programa Geologia do Brasil, 2013.

Manuscrito recebido em 22 de fevereiro de 2016 Revisado e aceito em 8 de março de 2017 